Haya: The Saudi Journal of Life Sciences

Abbreviated Key Title: Haya Saudi J Life Sci

ISSN 2415-623X (Print) |ISSN 2415-6221 (Online)

Scholars Middle East Publishers, Dubai, United Arab Emirates

Journal homepage: https://saudijournals.com

Original Research Article

\title{
UV-B Induced Changes to the Physiological and Phytochemical Parameters of Phyllanthus amarus Schum
}

\author{
N. Shanthi ${ }^{1 *}$, S. Murugesan ${ }^{1}$, S.M. Janetta Nithia ${ }^{2}$, M.Kotteswari ${ }^{1}$, S.Shyamala Gowri ${ }^{1,2}$ \\ ${ }^{1}$ PG and Research Department of Botany, Unit of Plant stress physiology, Pachaiyappa's College, Chennai-600 030, Tamil Nadu, India \\ ${ }^{2}$ Department of Botany, Sri Meenakshi Government Arts College for Women, Madurai, India
}

DOI: $10.36348 /$ sjls.2020.v05i12.001

| Received: 12.09.2020 | Accepted: 25.09.2020 | Published: 05.12.2020

*Corresponding author: N. Shanthi

\section{Abstract}

UV-B is a growing concern due to the rise in UV-B levels on the surface of the earth as a result of the loss of stratospheric ozone. Increased levels of UV-B radiation can in fact negatively alter plant physiological processes, growth and productivity. However, when researching the effects of UV-B on medicinal plants like Phyllanthus amarus and in the tropical area under field conditions, there are some curious phenomena have been discovered. Enhanced UV-B radiation has greatly improved the growth of $P$. amarus. The outcome of the photosynthetic pigment showed increased UV-B enhanced synthesis of Chlorophyll or the accumulation of Chlorophyll pigments in the treated plants compared to non UV-B treated plants. The concentration of UV-B absorbing pigments also increased due to enhanced UV-B radiation in $P$. amarus. The synthesis of secondary metabolites such as flavonoid and phenol content was increased under UV-B treatment as compared to control. The UV-B radiation enhances the grade of the medicinal plant by improving the medicinally active compounds. This enhanced impact of UV-B could be important to observe when studying the phytotherapeutic function of $P$. amarus in health aspects of human life.

Keywords: UV-B, Chlorophyll, Flavonoids, Phenol, Saponin, Alkaloids, Phyllanthus amarus.

Copyright (C) 2020 The Author(s): This is an open-access article distributed under the terms of the Creative Commons Attribution 4.0 International License (CC BY-NC 4.0) which permits unrestricted use, distribution, and reproduction in any medium for non-commercial use provided the original author and source are credited.

\section{INTRODUCTION}

The depletion of the ozone layer caused by CFCs and other ozone-depleting compounds increases the amount of UV-B radiation $(280-320 \mathrm{~nm})$ on the emission on the earth's surface. The UV-B radiation is one of the most critical abiotic stresses in the ecosystem and it's influence on all physiological and phytochemical parameters. On the other hand, the UVB effect of plants depends on plant species, the position where plants grow and the interactive action another environmental issue [1].

The result of UV-B on the tropical organism is an explicit link, since ozone depletion and corresponding improvement in UV-B are mostly in the low latitude region. UV-B decreased plant height, leaf area and plant dry weight increased auxiliary branching and curling of the leaf [2]. Metwally ([3] revealed that when an exposure of UV-B in a number of weeks, leaf area and plant dry weight of rice was considerably was significantly diminish .Several of the previous studies have agreed to react to UV-B irradiation with relevancy growth, production of dry matter and physiological and biochemical changes depending on the species $[4,5]$.
Many plant species are unaffected by UV-B irradiation and many others tend to be stimulated by their development and other biological processes $[6,7]$.

Measurements of various alternative key parameters like chlorophyll and antioxidant content and levels of UV-B engrossing compounds have additionally established to be helpful indicators of UVB tolerance or sensitivity, since these parameters show the foremost speedy response to UV-B stress [8]. UV-B affects the reduction of photosynthetic activity mainly associated with the degradation of PS II proteins. It may induce photobleaching and photodegradation of photosynthetic pigments [9]. Chlorophylls and carotenoids could also be adversely suffering from relative great amounts of UV-B, with carotenoids typically being less affected than chlorophylls [10].

In constant time, plants respond to environmental stress by synthesizing a variety of secondary metabolites for defense purpose. Ultraviolet (UV) radiation influences the accumulation of endogenous plant secondary metabolites [11, 12]. Several studies have investigated the UV-mediated 
accumulation of flavonoids and associated phenolics, alkaloids, terpenes, lignans, steroids, curcumines, saponins, phytosterol and glucosides. However, there is an increasing awareness that a far larger variety of metabolites accumulate in ultraviolet light exposed plants. Especially tropical plants have developed a variety of mechanisms to protect against UV-B induced damage. The impact of increased UV-B radiation on healthy plants in tropical regime has gained considerable attention in today's world.

Experiments on medicinal plants in tropical ecosystem have received huge attention in nowadays world. As a result of the impact of UV-B on medicinal plant analysis is extremely less compared to agricultural plants. P. amarus is one in every of the standard healthful plants belong to Euphorbiaceae family and it's a little annual herb full-grown on tropical and subtropical region. Because of its wide selection medicinal properties it's utilized in the Indian Ayurvedic systems from the traditional times. The plant extract primarily used for Jaundice, Anemia, Bronchitis, Leprosy, Asthma etc. We hypothesized that the impact of increased UV-B on growth, photosynthetic pigment synthesis and accumulation of phytochemical compounds would be greater than the UV-B radiation not received by the plant.

\section{MATERIALS AND METHODS Plant materials}

Certified seeds of Phyllanthus amarus obtained from the Farm aid, Chennai was shown in experimental plots in the Pachaiyapppa's College
Botanical Garden, Chennai. One set of plants was grown under ambient solar radiation and other under 20\% UV-B enhanced solar radiation.

\section{Plant growth and UV-B treatment}

The seeds were soaked overnight in the running water. Separate soil beds were prepared for control (ambient) and UV-B treatment and seeds were sown in these experimental plots. The plants were watered regularly and care was taken to avoid microbial or pest infection during the experimental period. Plants with the first foliage leaf stage were used for UV-B treatment. UV-B treatment was given to these plants for $4 \mathrm{hrs}$ daily from 10 a.m to 2 p.m. Treatment was continued under ambient solar radiation and $20 \% \mathrm{UV}-\mathrm{B}$ enhanced solar radiation supplemented by a Philips TL40W/12 sunlamp (Gloelampenfabrieken, Holland). The first formed leaves were collected at different time periods and all the physiological and biochemical analyses were carried out.

\section{Measurement of radiation}

A Li-Cor Li-188B quantum/radiometer (LiCor., Inc., USA) with suitable photodetector was used to measure all the visible and photosynthetically active radiation. Radiation below $400 \mathrm{~nm}$ was determined by an IL 700 radiometer with a SEE 400 photodiode detector (International Light Inc., USA).

\section{Determination of growth}

Shoot length was determined soon after the seedlings were uprooted. All the measurements were the mean of twenty randomly selected samples.

\section{Estimation of pigments \\ A. Chlorophyll}

Pigments were extracted in $80 \%$ acetone and the amount of total $\mathrm{Chl}$, Chl et al., Chl $b$ and carotenoid was quantified using the formulae of Wellburn and Lichtenthaler [13].
Chlorophyll $a \quad(\mathrm{mg} / \mathrm{l})$ :
Chlorophyll $b \quad(\mathrm{mg} / \mathrm{l})$ :
Total Chlorophyll (mg/l):
$\left(12.21 \times \mathrm{A}_{663}\right)-\left(2.81 \times \mathrm{A}_{646}\right)$
$\left(20.13 \times \mathrm{A}_{646}\right)-\left(5.03 \times \mathrm{A}_{663}\right)$
$\left(7.18 \times \mathrm{A}_{663}\right)+\left(17.32 \times \mathrm{A}_{646}\right)$

\section{B. Carotenoid}

The concentration of total amount of carotenoids was estimated in the $80 \%$ acetone extract by measuring the absorbance at $480 \mathrm{~nm}$. Mackinney's (14) formula was used to correct the Chl interference.

Carotenoids

$$
(\mathrm{mg} / \mathrm{l}): \quad 1000 \mathrm{~A}_{470}-(3.27 \mathrm{Chl} a)-(104 \mathrm{Chl} b)
$$

\section{Flavonoid}

Fresh leaf samples equivalent to $100 \mathrm{mg}$ were cut into small pieces and incubated overnight in $5 \mathrm{ml}$ of $80 \%$ acidified methanol (80:20:1 of methanol:water: $\mathrm{HCl})$ at $4^{\circ} \mathrm{C}$ in the dark. After centrifugation to remove debris, the absorbance at 315 $\mathrm{nm}$ was taken and the flavonoids content was expressed as $\mu \mathrm{g} / \mathrm{g}$ leaf fresh weight [15].

\section{Anthocyanin}

Anthocyanin were extracted from the leaves by grinding the leaves in $80 \%$ acidified methanol (80:20:1 of methanol:water:HCl). After centrifugation, the clear extract was used to estimate the concentration of anthocyanin by measuring the absorbance at 530 and $657 \mathrm{~nm}$, according to Mancinelli et al., [16].

$\mu \mathrm{g} / \mathrm{g}$ fresh weight: $\left(\mathrm{A}_{530}\right)-\left(0.3 \times \mathrm{A}_{657}\right)$ 


\section{Preparation of extracts}

The fresh leaves P. Amarus (Euphorbiaceae) of control and UV-B irradiated plant leaves were soaked individually at room temperature in methanol for $72 \mathrm{hrs}$ in the ratio of $4: 1$. The extract was filtered using Whatman filter paper. This $\mathrm{t}$ was repeated for 2 to 3 times and similar extracts were pooled together and concentrated at $45^{\circ} \mathrm{C}$ under reduced pressure using a vacuum rotary evaporator. The concentrated crude methanol extract was subjected to the preliminary phytochemical screening. The concentrated crude methanolic extracts were subjected to qualitative phytochemical analysis [17].

\section{Yield of methanol extracts}

The concentrated crude methanol extracts were weighed independently and stored in $4^{\circ} \mathrm{C}$ in the refrigerator until further usage.

\section{Qualitative phytochemical analysis}

The different qualitative chemical tests were performed for establishing the profile of the given extract for its chemical composition. The crude drug was redissolved in methanol and subjected to various phytochemical analyses. The standard protocols were used for qualitative analysis of samples to check for the presence of alkaloids, flavonoids, phenols, saponins, tannins and terpenoids.

\section{STATISTICAL ANALYSIS}

The data on cell viability were analyzed by using the one way ANOVA followed by the Dennett's multiple comparison tests with equal sample size by using SPSS 17.0. The difference was considered significant when $\mathrm{p}<0.005$. All the values were expressed as mean \pm standard deviation (S.D).

\section{RESULTS AND DISCUSSION}

Effects of increased UV-B radiation were studied on one of our native medicinal plants, $P$. amarus. The improvement in solar UV-B was $20 \%$ above ambient radiation. The analysis of growth parameters, biochemical constituents and synthesis of secondary metabolites, once exposure to increased solar UV-B, was disbursed at associate interval of five days.
All the parameters were analyzed once ten days from the onset of UV-B treatment.

\section{Changes in the growth characteristics}

The effect of enhanced UV-B radiation accelerates the shoot length in throughout the growth period (Fig 1). Where as in non UV-B treated plant showed the normal growth level.

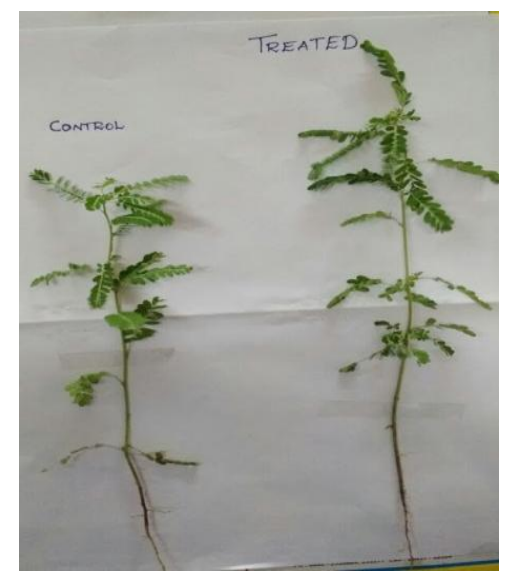

Fig-1: Typical morphological change in $P$. amarus grown under ambient and enhanced UV-B radiation

The growth was promoted from $10^{\text {th }}$ day onward. The difference between ambient and UV-B treated plants was found to be $30 \%$ (Fig 2). Elevated UV-B radiation directly affects plants through growth and development, biomass production, leaf characteristics and flowering time [18,19]. Sullivan and Teramura [20] stated that Gymnosperms tree species are tolerant of UV-B, whereas, some conifers show an increase in growth in response to UV-B radiation species. Many plant species are unaffected by UV-B radiation and a number of others are apparently aroused in their growth, however most species are vulnerable and damage, results such as rice and maize [21, 22]. Current studies under semi natural field conditions have found that UV-B radiation is not detrimental to growth and physiology [23]. Furthermore, UV-B radiation impacts are species specific and depend upon interaction with alternative environmental factors (1).

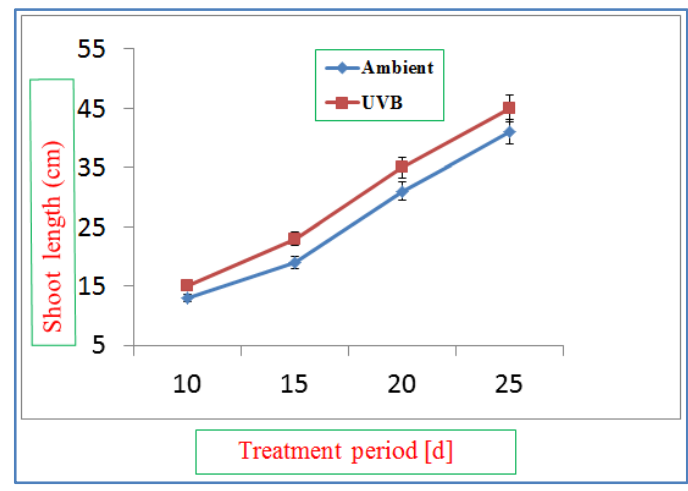

Fig-2: Changes in the shoot length in $P$. amarus grown under ambient and enhanced UV-B radiation. The values represent an average of 20 plants, Mean $\pm S E, n=20$ 


\section{Changes in photosynthetic pigment}

Changes in chlorophyll pigments are evidences of high UV radiation tolerance of analyzing plants. Chlorophyll-a and $\mathrm{b}$ are the main photosynthetic pigments in all higher plants. Whereas, carotenoids are the main UV-protecting pigments. Chlorophyll content levels have been determined to provide evidence of UV-B effects on chlorophyll metabolism. Spectral analysis showed that the total chlorophyll content of control plant was significantly less when compared to UV-B treated plants (Fig 3). The total chlorophyll content was promoted speedily in the $10^{\text {th }}$ Day to the $25^{\text {th }}$ day. UV-B stress exaggerated a production of chlorophyll, significantly $20^{\text {th }}$ day. On the $25^{\text {th }}$ day the chlorophyll synthesis was declining due to senescence. However, the percentage of promotion increased with an increase in plant growth. The content of chlorophyl was step by step exaggerated throughout the complete development period. An increase in chlorophyll following enhanced UV-B was observed in leaves of Bromus catharticus [24] and in wheat seedlings [25]. Chlorophyll synthesis, though addicted to the light absorbed by the phytochrome, could most likely be a result of the co-action between UV-B and phytochrome photo sensors [26]. The response of chlorophyll levels to exaggerated UV-B radiation depends on status and on the biological phase of plants [27]. Likewise, Li et al., [28] found that UV-B radiation increased the chlorophyll content synthesis during their growth of $P$. persicau. As a result of increased UV-B radiation, miRNA/genes rates have been elevated compared to untreated UV-B plants.

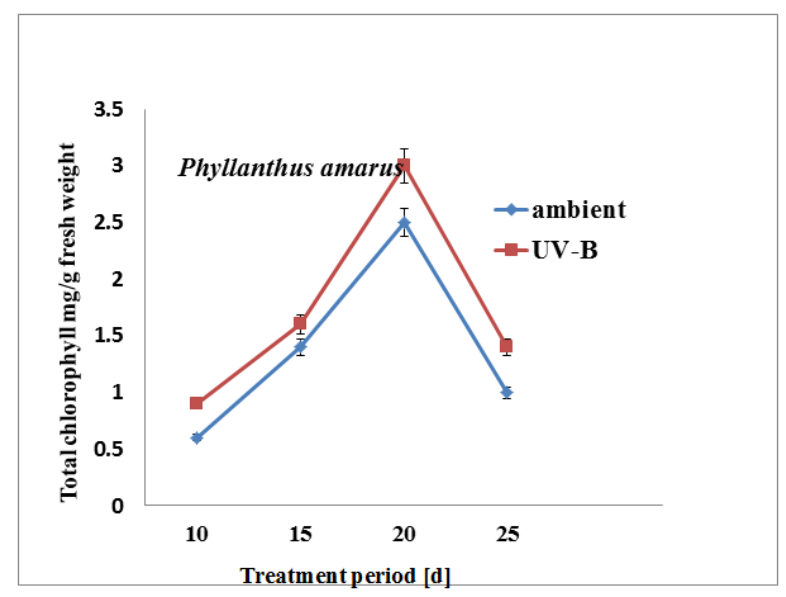

Fig-3: Changes in the total $\mathrm{Chl}$ content of $\boldsymbol{P}$. amarus grown under ambient and enhanced $U V-B$ radiation. The values represent an average of 3 independent measurements. Mean $\pm \mathrm{SE}, \mathrm{n}=3$.

Compared to the control plant, the synthesis of carotenoid pigment content in UV-B stressed plants are considerably higher up to the $25^{\text {th }}$ day (Fig 4). Such UV-B evoked pigment synthesis was twofold elevated than control plants. For photosynthetic organisms, the protecting role of carotenoids against high UV-B radiation is the standard and protective role of carotenoids in blue-green algae against UV-A radiation was reported by Monika Ehling-Schulz et al., [29]. UVB exposure accumulated the pigment synthesis capability of plants [30]. Recent studies have highlighted that ecologically relevant low UV-B levels will trigger the induction of synthetic resin compounds and also the accumulation of carotenoids and GS.

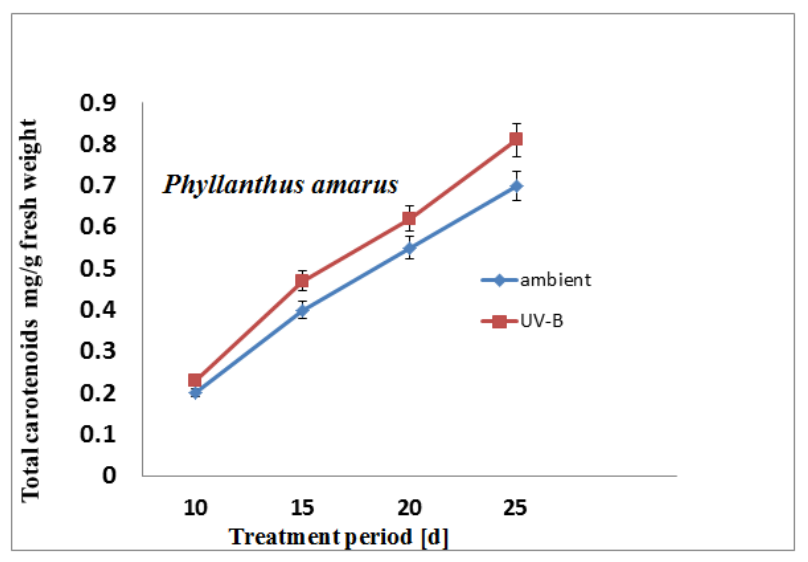

Fig-4: Changes in the total carotenoid content of $P$. amarus grown under ambient and enhanced UV-B radiation. The values represent an average of 3 independent measurements. Mean $\pm S E, n=3$ 


\section{Changes in non photosynthetic pigments}

The majority of the plants respond to UV-B radiation by producing UV-B absorbing compounds. The present investigation stated that UV-B radiation increased the accumulation of flavonoids in P. amaraus as compared to the ambient plants. The concentration flavonoids increased from $10^{\text {th }}$ Day onwards (Fig 5). The maximum 20\% increase of flavonoids was observed in UV-B treated plant at $25^{\text {th }}$ day as compared to control.

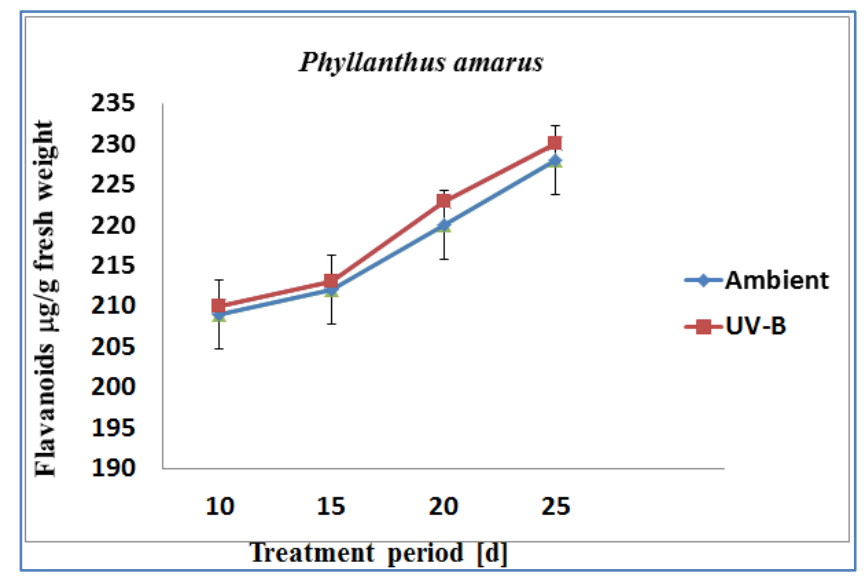

Fig-5: Changes in the flavonoids content of $P$. amarus grown under ambient and enhanced UV-B. The values represent an average of 3 independent measurements. Mean $\pm S E, n=3$

Flavonoids are probable antioxidants and are used as a vital interest recently, due to their impending useful effects on human health in fighting diseases. Several studies used acute increased UV-B levels and targeted on the rise of flavonoids together with anthocyanins, and hydroxycinnamic acids as UV-B protection by serving as active oxygen scavengers [ 31 , 32]. The stimulation of flavonoid biogenesis by UV-B is mainly due to of gene expression [33]. The UV-B stress activates the transcription of genes encoding the primary protein of the flavonoid biogenesis pathway,
Chalcone Synthase (CHS) [34], and enzymes that act downstream within the pathway [35]. Analysis accepted deoxyribonucleic acid sequence components within the promoter regions of flavonoid biogenesis genes that are required for UV-B, and transcription produced proteins that act within these components to mediate the reaction. Research has acknowledged DNA sequence elements in the promoter regions of flavonoid biosynthesis genes that are required for induction by UV-B, and transcription factor proteins that interact with these elements to mediate the reaction [35].

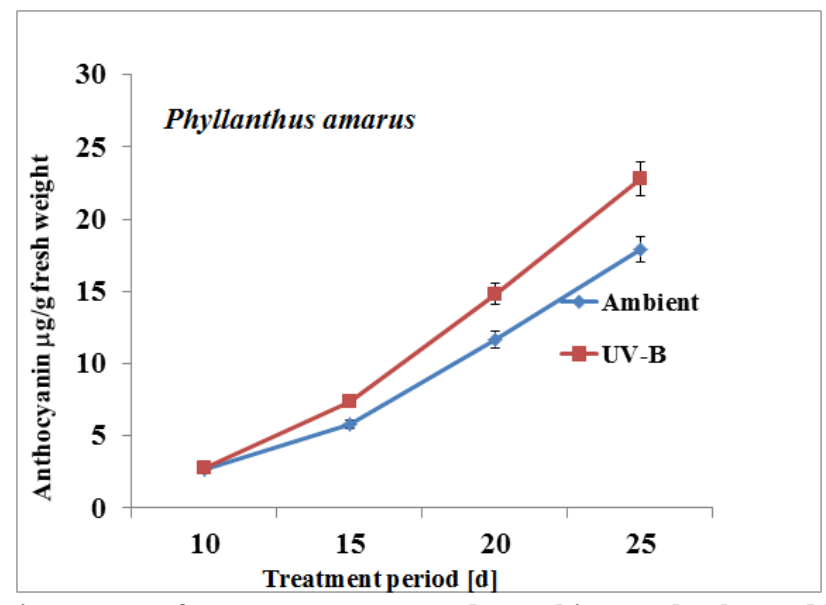

Fig-6: Changes in the anthocynin content of $P$. amarus grown under ambient and enhanced $U V$-B. The values represent an average of 3 independent measurements (Mean $\pm S E, n=3$ ).

The synthesis of anthocyanin content showed a maximum elevation in plants with UV-B stressed an increase in the amount of anthocyanin was determined at any point in the UV-B treated plant, with a limit of $25 \%$ at $25^{\text {th }}$ Days (Fig 6). Accumulation of anthocyanin was important due to UV-B interactions and plants. Most of the studies have shown that enhanced anthocyanin was chiefly because of UV-B irradiation impact. Ambasht and Agarwal [36] discovered that over $275 \%$ increase of anthocyanin content in maize. Anthocyanin has terribly weak absorption within the ultraviolet radiation-B regions and considered UV screens solely at very high concentration. EscobarBravo et al., [1] revealed that UV-B evoked accumulation of anthocyanin shield the chemical action equipment from the damaging result of UV-B radiation. 
Prefer to anthocyanin, flavonoid concentration was additionally raised in UV-B treated seedlings when eight days of treatment. In general, the flavonoid increase is linearly dependent on the UV-B effect [37]. Del Valle et al., [38] all over that flavonoid concentration will diminish the UV-B penetration and guard the photosynthetic apparatus up to some extent, however, if depends abreast of an intensity level, which can vary in numerous species. Likewise UV-B induction of anthocyanin accumulation was discovered conjointly in Arabidopsis [39], eggplant [40] and grape [41].
Phytochemical analysis of ethanol extracts of leaves of P.amarus

A preliminary phytochemical investigation of the ethanol extracts of leaves of $P$. amarus revealed the presence of flavonoids, tannins, phenolic compounds, alkaloids, glycosides, fats and carbohydrates. Phytochemical analysis of leaf extract of $P$. amarus showed the high quantity of secondary metabolites in the UV-B treated plant when compared to the control plant (Table 1).

Table-1: Comparative analysis of phytochemical compounds in methanol extracts of leaves of $P$. amarus

\begin{tabular}{|l|c|c|}
\hline \multicolumn{1}{|c|}{ Phytochemical test } & Control & Treated \\
\hline $\begin{array}{l}\text { I. Alkaloids } \\
\text { 1. Mayer's Test }\end{array}$ & + & +++ \\
\hline 2. Wagner's Test & + & +++ \\
\hline 3. Hager's test & + & +++ \\
\hline 4. Dragendorff's test & + & +++ \\
\hline $\begin{array}{l}\text { II. Flavonoids } \\
\text { 1. Alkaline reagent test }\end{array}$ & + & + \\
\hline $\begin{array}{l}\text { III. Fixed oil test } \\
\text { 1. Spot test }\end{array}$ & + & +++ \\
\hline $\begin{array}{l}\text { IV. Carbohydrate } \\
\text { 1. Fehling's test }\end{array}$ & + & +++ \\
\hline 2. Benedict's test & + & +++ \\
\hline $\begin{array}{l}\text { V. Glycosides } \\
\text { 1. Borntrages's test }\end{array}$ & + & +++ \\
\hline $\begin{array}{l}\text { VI. Saponins } \\
\text { 1. Foam test }\end{array}$ & + & +++ \\
\hline $\begin{array}{l}\text { VII. Phytosterols } \\
\text { 1. Libermann-Burhard's test }\end{array}$ & + & +++ \\
\hline $\begin{array}{l}\text { VIII. Phenols } \\
\text { 1. Ferric chloride test }\end{array}$ & + & +++ \\
\hline 2. Gelatin test & + & +++ \\
\hline 3. Lead acetate test & + Present| & + \\
\hline
\end{tabular}

Note: $+=$ present $+++=$ Present strongly

The synthesis secondary metabolites like flavonoids and phenol content were increased under UV-B treated condition when compared to control. Such increase was $0.5 \%$ higher in UV-B treated plants. At the same time phenol content was more as compared to flavonoid content in UV-B treated plants (Table 2).

Table-2: Comparative analysis of phenol and flavanoid in ethanol extracts of leaves of $P$. amarus

\begin{tabular}{|c|c|c|c|}
\hline S.No & Extract & $\begin{array}{l}\text { Phenol content }(\mathrm{mg} \mathrm{GAE} / \mathrm{g} \text { DW of Ethanol } \\
\text { Extract) }\end{array}$ & $\begin{array}{l}\text { Flavonoid content (mg QE/g } \\
\text { DW of Ethanol Extract) }\end{array}$ \\
\hline 1 & Control & $100.00 \pm 4.00$ & $146.02 \pm 11.99$ \\
\hline 2 & Treated & $133.33 \pm 6.11$ & $201.59 \pm 14.55$ \\
\hline
\end{tabular}

Values are mean of triplicates \pm Standard deviation. 


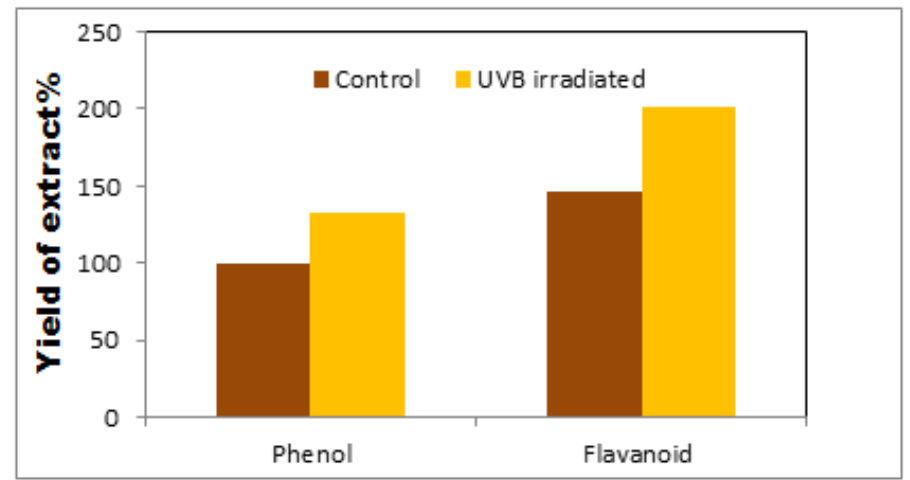

Fig-7: Comparative analysis of phenol and flavonoid contents of Methanol extracts of leaves of P. amarus

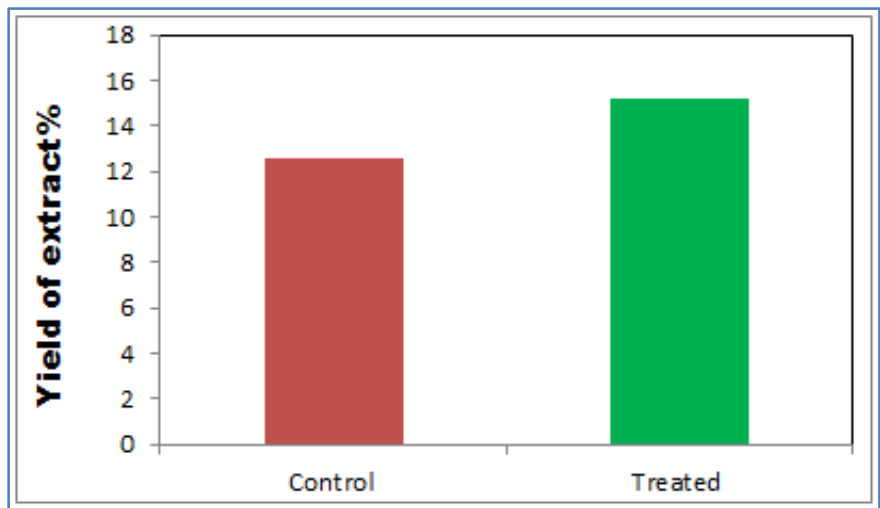

Fig-8: Comparative analysis of flavonoid contents of Methanol extracts of the leaves of $P$. amarus

The plant possesses a high potential for production of valuable phytocomponents under field condition to guard the plant from the damaging effects of UV-B radiation. UV-B exposure additionally led to elevated completely different phytochemical compounds like alkaloids, phenols, phytosterol and flavonoid (Figs. $7 \&$ 8). The improvement was thrice over non stressed plant. The experimental result evidenced that those phytochemical compounds are defence compound. Similar kind of results was projected by Kumari and Agarwal [42] the UV-B radiation having an efficiency to reinforce the amount of terpenoid phenyl propanoid and natural antioxidants.Turtola et al., [43] stated that spruce has high quantity of penolic compound in comparison to Scotch pine as a result of the previous species have higher screening capability against UV-B irradiation. Hagen et al., [44] stated that the results of post harvest UV-B irradiance with UV-B radiation and reportable the augmented price in phenolic content. The phenol will act as shielder after they exposed to UV-B radiation [45]. In other research Behn [46] ascertained that UV-B radiation improves the synthesis of terpenoids in the mint family. Johnson et al., [47] investigated the accumulation of terpenoid, glucoside in basil leaves. The optimum UV-B radiation augmented the production of Glyrrhizic acid, a triterpenoid in Glyrhiza uralesis [48]. The UV-B light induce alkaloid in C. roseus leaves [49]. $\mathrm{Zu}$ et al., [50] reported the augmented content of alkaloids in plant exposed to increased UV-B radiation. Phytochemical compounds are used synthesized by UV-B radiation, which act as UV-B absorbent and so capable protects the plant from the harmful impact of the plant. Increased UV-B radiation raises the elevated level of several individual flavonoids and phenolic acids anywhere they are contained in the Betula pendula response [51].

\section{CONCLUSION}

Plants have the ability to adapt the everchanging climate and improve the growth and physiological activity. Environmental factors affect the chemical composition and induce changes in the amount of secondary metabolites and promote the accumulation of bioactive compounds. It has increased the quality of medicinal plants. Therefore, this changing impact of UV-B may also be important to observe in the discovery of the phytotherapeutic activity of P. amarus, in the health aspects of human life.

\section{REFERENCES}

1. Escobar-Bravo, R., Klinkhamer, P. G., \& Leiss, K. A. (2017). Interactive effects of UV-B light with abiotic factors on plant growth and chemistry, and their consequences for defense against arthropod herbivores. Frontiers in Plant Science, 8, 278.

2. Furness, N. H., Upadhyaya, M. K., \& Ormrod, D. P. (1999). Seedling growth and leaf surface morphological responses of three rangeland weeds to ultraviolet-B radiation. Weed science, 427-434. 
3. Metwally, S. A., Shoaib, R. M., Hashish, K. I., \& El-Tayeb, T. A. (2019). In vitro ultraviolet radiation effects on growth, chemical constituents and molecular aspects of Spathiphyllum plant.Bulletin of the National Research Centre, 43(1), 94.

4. Mpoloka, S,W.(2008). Effects of prolonged UV-B exposure in plants. African Journal of Biotechnology, 7(25), 4874-4883.

5. Fedina, I., Hidema, J., Velitchkova, M., Georgieva, K., \& Nedeva, D. (2010). UV-B induced stress responses in three rice cultivars. Biologia plantarum, 54(3), 571-574.

6. Du, H., Liang, Y., Pei, K., \& Ma, K. (2011). UV radiation-responsive proteins in rice leaves: a proteomic analysis. Plant Cell Physiol, 52(2), 306316.

7. Lidon, F,C. (2012). Micronutrients' accumulation in rice after supplemental UV-B irradiation. J. Plant Inter, 7(1), 19-28.

8. Mosadegh, H., Trivellini, A., Lucchesini, M., Ferrante, A., Maggini, R., Vernieri, P., \& Mensuali Sodi, A. (2019). UV-B Physiological Changes Under Conditions of Distress and Eustress in Sweet Basil. Plants, 8(10), 396.

9. Strid, A.,\& Parra, KJ.(1992). Alteration in pigments content in leaves o f Pisum $\mathrm{u} \mathrm{m}$ w after exposure to supplememtary UVB. Piamt $\mathrm{CeB} \mathrm{P}$ kyool, 53, 1015-1023.

10. Sandmann, G. (2019). Antioxidant protection from UV-and light-stress related to carotenoid structures. Antioxidants, 8(7), 219.

11. Katerova, Z., Todorova, D., Tasheva, K., \& Sergiev, I. (2012). Influence of ultraviolet radiation on plant secondary metabolite production. Genet Plant Physiol, 2(3-4), 113-144.

12. Mao, B., Yin, H., Wang, Y., Zhao, T. H., Tian, R. R., Wang, W., \& Ye, J. S. (2017). Combined effects of $\mathrm{O} 3$ and $\mathrm{UV}$ radiation on secondary metabolites and endogenous hormones of soybean leaves. PLoS One, 12(8), e0183147.

13. Wellburn, A. R., \& Lichtenthaler, H. (1984). Formulae and program to determine total carotenoids and chlorophylls a and b of leaf extracts in different solvents. In Advances in photosynthesis research (pp. 9-12). Springer, Dordrecht.

14. Mackinney's, G. (1940). Criteria for purity of chlorophyll preparations. J. Biol. Chem, 132, 91109.

15. Mirecki, R. M., \& Teramura, A. H. (1984). Effects of ultraviolet-B irradiance on soybean: V. The dependence of plant sensitivity on the photosynthetic photon flux density during and after leaf expansion. Plant physiology, 74(3), 475-480.

16. Mancinelli, A. L., Yaniv, Z., \& Smith, P. (1967). Phytochrome and seed germination. I. Temperature dependence and relative $\mathrm{Pfr}$ levels in the germination of dark-germinating tomato seeds. Plant physiology, 42(3), 333-337.
17. Raaman, N. (2006). Phytochemical techniques. New India Publishing agency, New Delhi, India, 306.

18. Fagerberg, W. R., \& Bornman, J. F. (2005). Modification of leaf cytology and anatomy in Brassica napus grown under above ambient levels of supplemental UV-B radiation. Photochemical \& Photobiological Sciences, 4(3), 275-279.

19. Hectors, K., Prinsen, E., De Coen, W., Jansen, M. A., \& Guisez, Y. (2007). Arabidopsis thaliana plants acclimated to low dose rates of ultraviolet B radiation show specific changes in morphology and gene expression in the absence of stress symptoms. New Phytologist, 175(2), 255-270.

20. Sullivan, J. H., \& Teramura, A. H. (1992). The effects of ultraviolet-B radiation on loblolly pine. Trees, 6(3), 115-120.

21. Du, H., Liang, Y., Pei, K., \& Ma, K. (2011). UV radiation-responsive proteins in rice leaves: a proteomic analysis. Plant and cell physiology, 52(2), 306-316.

22. Lidon, F.C. (2012). Micronutrients' accumulation in rice after supplemental UV-B irradiation. J. Plant Inter, 7(1),19-28.

23. Björn, L. O., Widell, S., \& Wang, T. (2002). Evolution of UV-B regulation and protection in plants. Advances in Space Research,30(6), $1557-$ 1562.

24. Deckmyn, G., \& Impens, I. (1997). Combined effects of enhanced UV-B radiation and nitrogen deficiency on the growth, composition and photosynthesis of rye (Secale cereale). In $U V-B$ and Biosphere (pp. 235-240). Springer, Dordrecht.

25. Correia, C. M., Areal, E. L. V., Torres-Pereira, M. S., \& Torres-Pereira, J. M. G. (1999). Intraspecific variation in sensitivity to ultraviolet-B radiation in maize grown under field conditions: II. Physiological and biochemical aspects. Field crops research, 62(2-3), 97-105.

26. Mohr, H. (1986). Coaction between pigment systems REKGH Kronenberg (Ed.), Photomorphogenesis in Plants, Martinus Nijhoff, Netherlands, 547-564.

27. Rai, R., Meena, R.P., Smita, S.S., Shukla, A., Rai, S.K., \& Pandey-Rai, S. (2011). UV-B and UV-C pre-treatments induce physiological changes and artemisinin biosynthesis in Artemisia annua L. An antimalarial plant. J Photochem Photobiol B $105,216-225$

28. Li, S., Shao, Z., Fu, X., Xiao, W., Li, L., Chen, M., Sun, M., Li, D., \& Gao. (2017). Identification and characterization of Prunus persica miRNAs in response to UVB radiation in greenhouse through high-throughput sequencingBMC Genomics, 18, 938.

29. Monika Ehling-Schulz \& Siegfried Scherer. (1999). UV protection in cyanobacteria, European Journal of Phycology, 34(4), 329-338.

30. Hectors, K., Prinsen, E., Coen, W.D., Jansen, M.A.K., \& Guisez, Y. (2007). Arabidopsis thaliana 
plants acclimated to low dose rates of ultraviolet B radiation show specific changes in morphology and gene expression in the absence of stress symptoms. New Phytol, 175,255-270.

31. Sharma, A., Shahzad, B., Rehman, A., Bhardwaj, R., Landi, M., \& Zheng, B. (2019). Response of phenylpropanoid pathway and the role of polyphenols in plants under abiotic stress. Molecules, 24(13), 2452.

32. Jenkins. (2014). The UV-B Photoreceptor UVR8: From Structure to Physiology Gareth. The Plant Cell, 26, 21-37,

33. Zhang, X., Abrahan, C., Thomas, A., Colquhoun., \& Liu, C. (2017). A Proteolytic Regulator Controlling Chalcone Synthase Stability and Flavonoid Biosynthesis in Arabidopsis. Plant Cell, 7, 29(5), 1157-1174.

34. Schreiner, M., Krumbein, A., Mewis, I., Ulrichs, C.,\& Huyskens-Keil, S. (2009). Short-term UV-B radiation effects on secondary metabolism in different organs of Tropaeolum majus L. Innovat. Food Sci. Emerg. Technol, 10,93-96.

35. Hartmann, U., Sagasser, M., Mehrtens, F., Stracke, R., \& Weisshaar, B. (2005). Differential combinatorial interactions of cis-acting elements recognized by R2R3-MYB, BZIP, and BHLH factors control light-responsive and tissue-specific activation of phenylpropanoid biosynthesis genes. Plant Molecular Biology, 57, 155-171.

36. Ambasht, N.K., \& Agrawal, M. (1998). Physiological and biochemical responses of orghum vulgare plants to supplemental ultravioletB radiation, Can. J. Bot, 76, 1290-1294.

37. Feng, H., Shiwen, L.I., Xue, L., \& An Xunling, Wang, L. (2007). The interactive effects of enhanced UV-B radiation and soil drought on spring wheat, South African Journal of Botany, 73(10),429-434.

38. Del Valle, J. C., Buide, M. L., Whittall, J. B., Valladares, F., \& Narbona, E. (2020). UV radiation increases phenolic compound protection but decreases reproduction in Silene littorea. PloS one, 15(6), $\mathrm{e} 0231611$.

39. Fuglevand, G., Jackson, J. A., \& Jenkins, G. I. (1996). UV-B, UV-A, and blue light signal transduction pathways interact synergistically to regulate chalcone synthase gene expression in Arabidopsis. The Plant Cell, 8(12), 2347-2357.

40. Toguri, T., Umemoto, N., Kobayashi, O., \& Ohtani, T. (1993). Activation of anthocyanin synthesis genes by white light in eggplant hypocotyl tissues, and identification of an inducible P-450 cDNA. Plant molecular biology, 23(5), 933946.

41. Kataoka, I., Sugiyama, A., \& Beppu, K. (2003). Role of ultraviolet radiation in accumulation of anthocyanin in berries of'Gros Colman'grapes (Vitis vinifera L.). Journal of the Japanese Society for Horticultural Science, 72(1), 1-6.
42. Kumari, R., \& Agrawal, S. B. (2011). Comparative analysis of essential oil composition and oil containing glands in Ocimum sanctum L.(Holy basil) under ambient and supplemental level of UV-B through gas chromatography-mass spectrometry and scanning electron microscopy. Acta Physiologiae Plantarum, 33(4), 1093-1101.

43. Turtola, S., Rousi, M., \& Pusenius, J. (2005). Genotypic variation indrought response of willows grown under ambient and enhanced UV-B radiation. Environmental and Experimental Botany (in press).

44. Hagen, S. F., Borge, G. I. A., Bengtsson, G. B., Bilger, W., Berge, A., Haffner, K., \& Solhaug, K. A. (2007). Phenolic contents and other health and sensory related properties of apple fruit (Malus domestica Borkh., cv. Aroma): Effect of postharvest UV-B irradiation. Postharvest Biology and Technology, 45(1), 1-10.

45. Kataria, S., Jajoo, A., \& Guruprasad, K. N. (2014). Impact of increasing Ultraviolet-B (UV-B) radiation on photosynthetic processes. Journal of Photochemistry and Photobiology B: Biology, 137, 55-66.

46. Behn, H., Albert, A., Marx, F., Noga, G., \& Ulbrich, A. (2010). Ultraviolet-B and photosynthetically active radiation interactively affect yield and pattern of monoterpenes in leaves of peppermint (Menthax piperita L.). Journal of agricultural and food chemistry,58(12), 73617367.

47. Johnson, CB., Kirby, J., Naxakis, G., \& Pearson, S. (1999). Substantial UV-B-mediated induction of essen-tial oils in sweet basil ( Ocimum basilicum L). Phytochemistry, 51(4), 507-510.

48. Afreen, F., Zobayed, S. M. A., \& Kozai, T. (2005). Spectral quality and UV-B stress stimulate glycyrrhizin concentration of Glycyrrhiza uralensis in hydroponic and pot system. Plant Physiology and Biochemistry, 43(12), 1074-1081.

49. Ouwerkerk, P. B., Hallard, D., Verpoorte, R., \& Memelink, J. (1999). Identification of UV-B lightresponsive regions in the promoter of the tryptophan decarboxylase gene from Catharanthus roseus. Plant Molecular Biology, 41(4), 491-503.

50. Zu, Y. G., Pang, H. H., Yu, J. H., Li, D. W., Wei, X. X., Gao, Y. X., \& Tong, L. (2010). Responses in the morphology, physiology and biochemistry of Taxus chinensis var. mairei grown under supplementary UV-B radiation. Journal of Photochemistry and Photobiology B: Biology, 98(2), 152-158.

51. De La Rosa, T. M., Julkunen- Tiitto, R., Lehto, T., \& Aphalo, P. J. (2001). Secondary metabolites and nutrient concentrations in silver birch seedlings under five levels of daily UV- B exposure and two relative nutrient addition rates. $\mathrm{New}$ Phytologist, 150(1), 121-131. 